\title{
Dinâmica dos financiamentos habitacionais nos municípios do Rio Grande do Sul de 2006 a 2010: uma avaliação do Programa "Minha Casa, Minha Vida"
}

\author{
Cátia Fernanda da Silva \\ Unisinos \\ Tiago Wickstrom Alves \\ Unisinos
}

\begin{abstract}
O déficit habitacional no Brasil é um problema crônico, apesar dos diversos programas implementados a fim de solucionar essa questão. Este estudo objetiva analisar os elementos impulsionadores dos financiamentos habitacionais e seus impactos, em termos regionais, no estado do Rio Grande do Sul, no período de 2006 a 2010, por meio da combinação de três procedimentos: o método estrutural-diferencial, a técnica de krigagem e a regressão espacial. Os resultados indicam que as faixas de crédito que mais cresceram foram as de valor intermediário, que os municípios de menor nível de renda foram os mais beneficiados com o crédito e que houve um deslocamento dos valores dos imóveis para as regiões menos valorizadas, reduzindo as desigualdades regionais. Ou seja, o programa "Minha Casa, Minha Vida" intensificou o volume de crédito, mas não alterou os aspectos estruturais dos financiamentos.
\end{abstract}

Palavras-chave: financiamento habitacional; programa "Minha Casa, Minha Vida"; política habitacional.

Dinámica de la financiación para viviendas en los municipios de Rio Grande do Sul: una evaluación del programa "Mi Casa, Mi Vida"

El déficit de vivienda en Brasil es un problema crónico, a pesar de los diversos programas implementados con el fin de resolver esa cuestión. Este estudio tiene como objetivo analizar los elementos impulsores de la financiación para viviendas y sus impactos, em términos regionales, en el estado de Rio Grande do Sul, en el período de 2006 a 2010, por medio de la combinación de tres procedimientos: el método estructural-diferencial, la técnica de krigeaje y la regresión espacial. Los resultados indican que los rangos de crédito que tuvieron mayor crecimiento fueron los de valor intermedio, que los municipios con nivel de ingresos más bajo fueron los que tuvieron mayor beneficio con el crédito y que hubo un cambio de los valores de las viviendas para las regiones menos valoradas, con reducción de las desi-

Artigo recebido em 1ํㅗ. 2012 e aceito em 4 out. 2013.

Rev. Adm. Pública - Rio de Janeiro 48(1):27-54, jan./fev. 2014 
gualdades regionales. Es decir, el programa brasileño "Mi Casa, Mi Vida" ha intensificado el volumen de crédito, pero no ha cambiado los aspectos estructurales de la financiación.

Palabras clave: financiación para vivienda; programa "Mi Casa, Mi Vida"; política de vivienda.

Dynamics of housing finances in the towns of Rio Grande do Sul: an evaluation of the program "My House, My Life"

Housing deficit is a chronic problem in Brazil, despite the various programs implemented in order to solve this issue. This study aims to analyze the driving forces for housing finances and their impacts, on a regional basis, on the state of Rio Grande do Sul, within the period from 2006 to 2010, by combining three procedures: the shift-share method, the kriging technique, and spatial regression. The results indicate that the credit ranges with more marked increase were those having an intermediate value, that the towns with lower income level benefited the most from the credit, and that there has been a shift in real estate values towards lower-price regions, reducing regional inequalities. That is, the Brazilian program "My House, My Life" has increased credit volumes, but it has not modified the structural aspects of finances.

KEYWORDs: housing finance; program "My House, My Life"; housing policy.

\section{Introdução}

A precariedade habitacional é um problema crônico no contexto das questões urbanas brasileiras e a solução para esse déficit não deve estar focada apenas na provisão de moradias (Warnock e Warnock, 2008). O planejamento público no Brasil, ao longo das últimas décadas, tem incrementado diversas políticas habitacionais com o intuito de amenizar esse problema, sendo a mais recente o Programa "Minha Casa, Minha Vida" (PMCMV), que foi implantado em 2009 (Brasil, 2009b).

Esse programa tem por finalidade criar mecanismos de incentivo à produção e à aquisição de novas unidades habitacionais pelas famílias com renda de até 10 salários mínimos. A meta, para os anos de 2009 e 2010, era a construção de um milhão de moradias, e, desse total, 40\% destinava-se a famílias com renda de até três salários mínimos (Brasil, 2009c).

O presente artigo tem por objetivo analisar os elementos impulsionadores dos financiamentos habitacionais e seus impactos em termos regionais, no Rio Grande do Sul, no período de 2006-10. O período compreende os dois anos anteriores e os dois anos iniciais do PMCMV, possibilitando também avaliar o impacto que o programa apresentou na dinâmica dos financiamentos.

Neste estudo, o déficit habitacional será compreendido como a necessidade de aumento do estoque de moradias e da substituição daquelas que apresentam condições insalubres de sobrevivência. Esse conceito vai ao encontro do estudo desenvolvido pela Fundação João Pinheiro (Brasil, 2009a), que leva em consideração as necessidades para a solução da questão habitacional, num dado momento do tempo, e que serve de base para grande parte dos estudos desenvolvidos no Brasil acerca do tema. Ou seja, o conceito de déficit não está reduzido ao 
conceito de "ser ou não proprietário". Em razão disso, vale ressaltar que "qualquer política pública na área habitacional não pode deixar de considerar a existência do alto porcentual de domicílios não ocupados" (Alves e Cavenaghi, 2006:269).

A relevância do tema em estudo decorre do fato de que: i) a sociedade brasileira é marcada por uma profunda segregação socioespacial do espaço urbano (Botelho, 2007); ii) a eficácia de uma política habitacional requer que os investimentos habitacionais sejam direcionados para as regiões mais pobres do país e para as pessoas de menor renda (Gonçalves, 1998), logo, é relevante avaliar o impacto do Programa "Minha Casa, Minha Vida" em termos espaciais; iii) ainda, como a moradia própria — segundo Pereira (2007), Silva (1989) e Gonçalves (1998) — é o espaço que permite que a família expresse sua cultura e consiga definir seu papel na sociedade onde vive - então, é fundamental que se investigue a efetividade dos programas habitacionais.

A escolha do Rio Grande do Sul se deve ao fato de o estado apresentar o segundo menor déficit habitacional urbano do país. O déficit habitacional, no Brasil, em 2000 (ano do último censo no Brasil e que foi base para o estabelecimento do PMCMV), era de $13,15 \%$ do total de residências, sendo $11,08 \%$ nas áreas urbanas. Considerando apenas imóveis urbanos, foco desta pesquisa, Santa Catarina é o estado da federação com menor déficit, 6,41\%, seguido pelo Rio Grande do Sul, com 6,74\% (Brasil, 2009a). De acordo com o CBIC (2011), embora seja observada uma menor necessidade de suprimento de moradias nos estados da região Sul, Paraná, Santa Catarina e Rio Grande do Sul apresentaram um desempenho acima da média no PMCMV, o que parece ser um contrassenso. Destaca-se que a divisão dos recursos do Programa para as famílias de menor renda foi feita com base no déficit habitacional do ano 2000 e, assim, se estabeleceu a meta a ser realizada em cada município. A implementação de um volume tão intenso de recursos deve causar modificações na dinâmica de valorização regional dos imóveis, sendo necessário determinar o sentido dos vetores de valores para que se possa avaliar o impacto desta política em termos espaciais.

A introdução deste artigo é seguida pelas considerações acerca da política habitacional brasileira, na seção 2 . A seção 3 apresenta a metodologia empregada neste estudo. A seção 4 mostra os resultados obtidos com a aplicação do método estrutural-diferencial e as técnicas de krigagem, enquanto a seção 5 mostra os resultados da regressão espacial. Por fim, a seção 6 traz as considerações acerca da avaliação proposta.

\section{A política habitacional brasileira}

Até a década de 1930, a oferta habitacional no Brasil era de responsabilidade da iniciativa privada. O capital destinado a esses empreendimentos era originário das atividades agropecuárias e mercantis, e o mercado imobiliário era uma alternativa de investimento. Logo, as moradias ofertadas estavam voltadas às classes mais abastadas. Com o fim da Primeira Repú- 
blica, o Estado passou a intervir nessa produção, o que acabou marginalizando o setor rentista (Botelho, 2007).

A primeira iniciativa de prover habitações para a população de baixa renda, em âmbito nacional, foi a criação da Fundação Casa Popular (FCP), em 1946 (Silva, 1989). Em 1961, criou-se o Plano de Assistência Habitacional e o Instituto Brasileiro de Habitação (IBH) (Azevedo e Andrade, 1982). Em um processo de evolução, em 1964, foi criado o Sistema Financeiro de Habitação (SFH), que se constituiu num "mecanismo de captação de poupança de longo prazo para investimentos habitacionais" (Santos, 1999:10).

Como programas complementares têm-se: i) o caso do Programa de Financiamento de Lotes Urbanos (Profilurb), em 1975, voltado à população de baixa renda, incorporando famílias com renda informal e abaixo do limite estabelecido pelos programas das Cohabs; ii) o Programa de Erradicação da Sub-Habitação (Promorar), em 1979, que se constituiu em uma estratégia voltada às famílias que ocupavam ilegalmente a terra urbana.

Após a extinção do BNH, em 1986, o governo criou o Programa Nacional de Mutirões Habitacionais, que era executado pela Secretaria Especial de Ação Social (Seac). Esse programa consistia na construção de casas nas periferias das cidades (principalmente), através do sistema de ajuda mútua (Braga, 1995).

Durante o governo do presidente Fernando Collor de Mello (1990-92), houve um agravamento da crise das políticas públicas na área de habitação, com algumas mudanças superficiais no SFH, e programas de habitação popular caracterizados pela má utilização dos recursos públicos. No governo Itamar Franco, os programas habitacionais passaram a ser controlados pelo Ministério do Bem-Estar Social, que exigia a participação de conselhos formados pelos governos locais. Isso fez com que houvesse um maior controle social e transparência desses programas (Habitar-Brasil e Morar-Município), que foram mantidos na gestão posterior ou que serviram de base para a formulação de programas semelhantes (Santos, 1999).

Entre os anos de 1995 e 1998, os dois principais programas habitacionais foram o Pró-Moradia e Habitar-Brasil, que passaram a incumbência de estados e municípios e a apresentação de projetos à esfera federal, que decidia sobre a liberação dos financiamentos (Santos, 1999).

Em 1999, foi criado o Programa de Arrendamento Residencial (PAR) voltado à construção de conjuntos habitacionais de pequeno porte localizados na malha urbana (Bonates, 2008). O Programa objetivava ampliar o acesso à moradia para a população de baixa renda sob a forma de arrendamento residencial com opção de compra.

Já no governo Lula, em 2003, foi criado o Ministério das Cidades, órgão responsável pelas Políticas de Desenvolvimento Urbano e Setorial de Habitação (ainda vigente em 2012), que visava a promover condições de acesso à moradia digna para toda a população, principalmente de baixa renda, tendo como componentes principais a Integração Urbana de Assentamentos Precários, a urbanização, a regularização fundiária e a inserção de assentamentos precários, bem como a provisão da habitação e a integração da política de habitação à política de desenvolvimento urbano (Brasil, 2004:29). 
O Programa "Minha Casa, Minha Vida" (PMCMV) foi implementado em 2009. Deriva do Programa de Aceleração do Crescimento (PAC), implantado em 2007, em que uma das propostas de atuação era a criação de uma linha de crédito específica para permitir o acesso à moradia por parte da população de baixa renda. Assim, o PMCMV surgiu com a finalidade de criar mecanismos para incentivar a construção e a compra de novas unidades habitacionais para famílias com renda mensal de até 10 salários mínimos, em qualquer cidade do território nacional. A meta inicial era produzir um milhão de moradias (Rolnik, 2010).

Hirata (2009) ressalta que a distribuição dos recursos destinados ao PMCMV se deu com base no déficit habitacional por regiões do país e por faixas de renda. Além disso, o direcionamento desses recursos é feito pela Caixa Econômica Federal.

Com relação à renda para enquadramento no Programa, ela se situa na faixa de $\mathrm{R} \$$ 465,00 a R \$ 5.000,00 para financiamentos vinculados a imóveis situados nos municípios integrantes das regiões metropolitanas ou equivalentes, municípios-sede de capitais estaduais, ou municípios com população igual ou superior a 250 mil habitantes. Para os demais municípios, o limite de renda fica entre $\mathrm{R} \$ 465,00$ e $\mathrm{R} \$ 3.900,00$. Há de se ressaltar também que o comprometimento financeiro do mutuário não pode ultrapassar $30 \%$ da renda familiar mensal bruta (Caixa, 2011).

Ou seja, ao longo do século XX, foram várias as tentativas para diminuir o déficit habitacional no Brasil. Embora tenham contribuído para tal, não foram capazes de eliminá-lo. Conforme os dados da Fundação João Pinheiro (FJP), em 2000, o déficit era de aproximadamente 6 milhões de residências, o que representava 13,15\% do total de domicílios (Fundação João Pinheiro, apud Brasil, 2009a). No final da década de 2000, foi lançado o PMCMV, o programa mais amplo e de maior inversão de recursos das últimas décadas e que ainda estava em andamento em 2012. Portanto, os reais impactos desse Programa ainda estão sujeitos a avaliações.

A seção seguinte apresenta os procedimentos metodológicos utilizados para avaliar o efeito do PMCMV na dinâmica regional dos preços e volumes de financiamentos, no Rio Grande do Sul.

\section{Procedimentos metodológicos}

Para o estudo proposto, optou-se por uma combinação de três procedimentos, que são: método estrutural-diferencial, técnicas de krigagem e regressão espacial. A figura 1 sintetiza a estrutura da pesquisa explicitando os objetivos, os métodos mencionados e a interligação entre eles, o que será esclarecido nas subseções seguintes. 
Figura 1

Síntese dos procedimentos utilizados na pesquisa

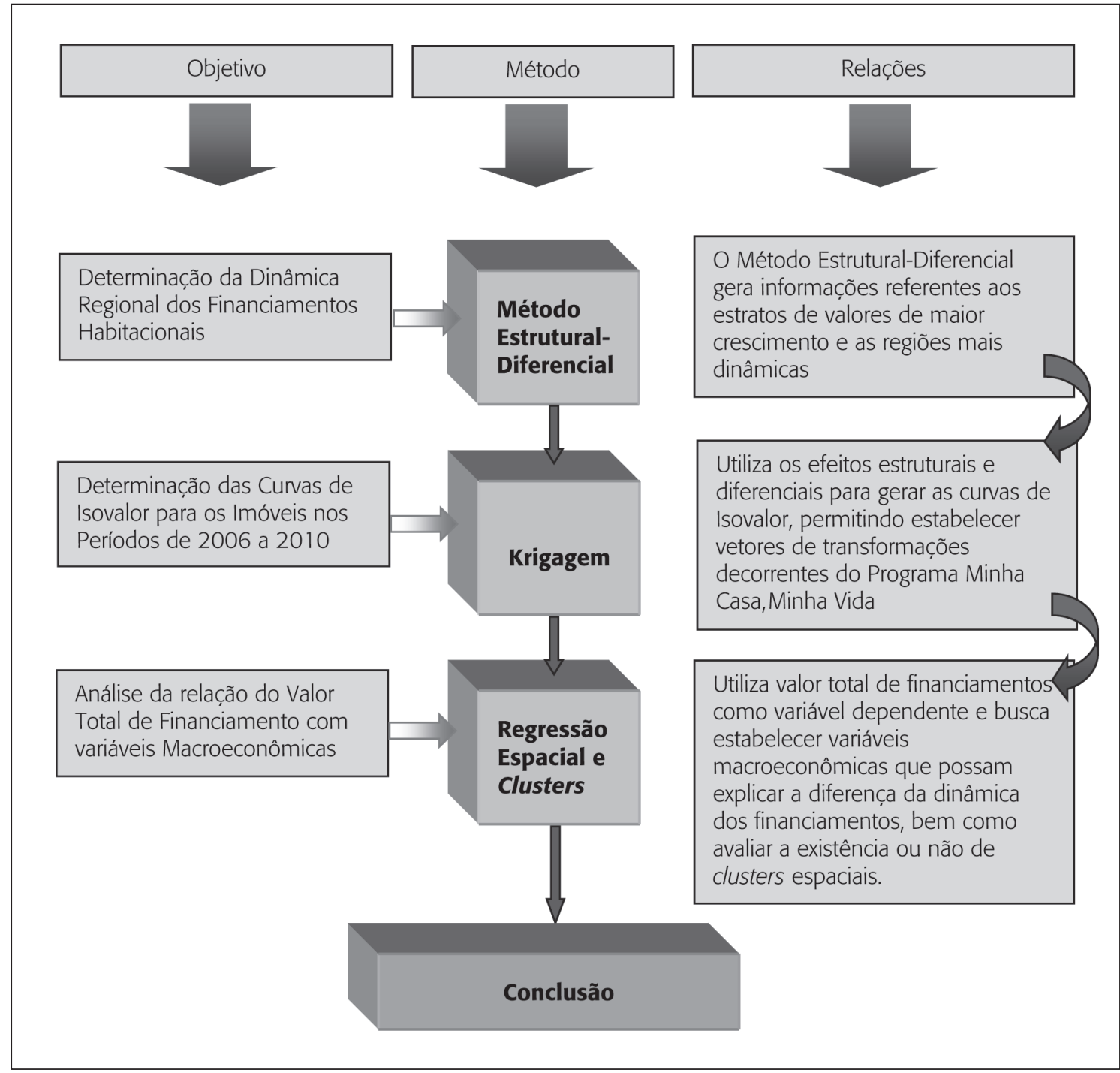

Fonte: Elaboração própria.

\subsection{Método estrutural-diferencial}

O método estrutural-diferencial decompõe o crescimento das variáveis de análise em dois fatores. Um interno, associado à competitividade da região em si, e outro externo, vinculado ao dinamismo das atividades em relação às demais. O primeiro é denominado efeito diferencial, 
pois indica uma capacidade de a região crescer mais do que a média das demais. O segundo, quando uma região tem seu crescimento impulsionado por possuir setores que são dinâmicos em nível nacional, isto é, que crescem mais do que os demais setores, é denominado efeito estrutural (Souza e Rodrigues, 2004).

O emprego desse método é bastante difundido, sendo utilizado por economistas regionais e de economia internacional, geógrafos, planejadores urbanos e regionais, cientistas regionais, analistas de desenvolvimento. Alguns autores que utilizaram esse método são: Brown (1969), Lodder (1972), Dinc e Haynes (1999), Nazara e Hewings (2004), Mulligan e Molin (2004) e Fotopoulos (2007). Entretanto, há de se ressalvar que, apesar de mostrar quais os setores que estão crescendo ou diminuindo na região, o método estrutural-diferencial não apresenta relação de causa e efeito (Dinc e Haynes, 1999).

No Brasil, esse método foi utilizado em estudos desenvolvidos por Alves (1998), Pereira (1999), Sobral, Peci e Souza (2006), Souza (2007), Hersen e Lima (2009). Segundo os autores, o método estrutural-diferencial não é uma teoria explicativa do crescimento regional, mas se constitui num método de análise para identificar os fatores que influenciaram esse crescimento e, além disso, "se essa performance está condicionada ao desempenho da economia nacional, à estrutura produtiva local ou à presença de vantagens locacionais específicas que dão dinamismo à região" (Hersen e Lima, 2009:32).

Para o estudo proposto, o método estrutural-diferencial é utilizado com o fim específico de identificar quais são os municípios que apresentam um maior dinamismo com relação aos valores de financiamentos habitacionais concedidos pela Caixa Econômica Federal, entre os anos de 2006 e 2010.

O método estrutural diferencial foi baseado nos valores dos imóveis transacionados em cada município com o total financiado no estado, por faixa de valor de imóvel. O modelo utilizado é assim especificado:

Variação Real dos Valores dos Imóveis:

$$
\Delta V_{i j}=\Delta_{t} V_{i j}+\Delta_{e} V_{i j}+\Delta_{d} V_{i j}
$$

Variação Teórica dos Valores de Imóveis:

$$
\Delta_{t} V_{i j}=V_{i j}^{0}\left(v_{i j}-1\right) \therefore v_{i j}=V_{i j}^{t} / V_{i j}^{0}
$$

Variação Estrutural dos Valores de Imóveis:

$$
\Delta_{e} V_{i j}=V_{i j}^{0}\left(v_{i n}-v\right) \therefore v_{i n}=V_{i n}^{t} / V_{i n}^{0}
$$

Variação Diferencial dos Valores de Imóveis:

$$
\Delta_{d} V_{i j}=V_{i j}^{0}\left(v_{i j}-v_{i n}\right)
$$

Onde:

$F_{i}$ - representa a faixa de valor $i$; 
$M_{j}$ - representa o município j;

$V_{i j}$ - valor dos imóveis transacionados via financiamento habitacional na Caixa, na faixa de valor $i$ do município $j$;

$V_{r j}$ - valor total dos imóveis financiados pela Caixa no município $j$;

$V_{i n}$ — total dos imóveis financiados pela Caixa na faixa de valor $i$;

$V_{n}$ - valor total dos imóveis financiados no Estado.

A variável é o volume total ${ }^{1}$ de imóveis financiados pela Caixa Econômica Federal no Rio Grande do Sul, por município, limitando-se essa análise aos imóveis cujo valor venal se encontra num patamar inferior a R $\$ 500$ mil, atual teto de enquadramento para financiamentos dentro do Sistema Financeiro da Habitação (SFH). A obtenção dos dados para esta análise foi feita junto à Caixa Econômica Federal, que autorizou a sua utilização para fins desta pesquisa.

A partir dos efeitos diferenciais, estruturais e líquidos é possível identificar as faixas de imóveis mais dinâmicas, a competitividade dos municípios gaúchos no desenvolvimento habitacional e a dinâmica de deslocamento da concentração e/ou dispersão do volume de financiamentos nos municípios do Rio Grande do Sul.

Os resultados desta análise servem de base para a construção de curvas de isovalor, elaboradas com o efeito líquido observado e construídas a partir de técnicas de krigagem, procedimento descrito na subseção que segue.

\subsection{Construção das curvas de isovalor através de krigagem}

A krigagem é um método de estimativa por médias móveis, constituindo-se num processo de estimativa de valores de variáveis distribuídas no espaço e/ou no tempo, a partir de valores adjacentes, enquanto esses são considerados interdependentes pelo semivariograma (Landim, 2003). Seu uso expandiu-se com sucesso no mapeamento de solos, mapeamento hidrológico, mapeamento atmosférico e campos correlatos.

Segundo Druck e colaboradores (2004), existem três passos a serem seguidos num estudo que emprega técnicas de krigagem, que são:

a) análise exploratória dos dados;

b) análise estrutural (modelagem da estrutura de correlação espacial);

c) interpolação estatística da superfície.

\footnotetext{
${ }^{1}$ Volume total de imóveis corresponde ao somatório do valor venal de todos os imóveis financiados pela Caixa, em todas as suas linhas de crédito imobiliário. Esses dados foram obtidos junto à Caixa, em dezembro de 2010.
} 
A krigagem se diferencia de outros métodos de interpolação em razão de estimar uma matriz de covariância espacial que determina os pesos atribuídos às diferentes amostras, a vizinhança a ser considerada no procedimento inferencial e o erro associado ao valor estimado. Além disso, fornece estimadores com propriedades de não tendenciosidade e eficiência (Druck et al., 2004). Sendo o estimador de krigagem do tipo Blue (best linear unbiased estimator), é chamado linear por ser formado por uma combinação linear dos dados (Andriotti, 2005) na forma:

$$
Z_{k}^{*}=\sum_{i=1}^{n} \lambda_{i} \cdot z\left(x_{i}\right)
$$

Onde:

$\lambda_{i}$ são os ponderadores;

$z\left(x_{i}\right)$ são os dados experimentais;

$n$ é o número total de dados experimentais;

$Z_{k}^{*}$ é o estimador de krigagem.

Sendo a Condição de Universalidade: $\sum_{i=1}^{n} \lambda_{i}=1$ e a Condição de Otimalidade dada por: $\sigma_{k}^{2}=E\left(Z-Z_{k}^{*}\right)^{2}$.

Considerando que "os pesos ótimos são encontrados pela solução de um conjunto de equações lineares, cujos coeficientes são função do variograma e da localização das amostras em relação ao bloco a ser estimado" (Andriotti, 2005:137), a variância da krigagem será:

$$
\sigma_{k}^{2}=\sum_{i=1}^{n} \lambda_{1} \bar{\gamma}\left(x_{i}, V\right)+\mu-\bar{\gamma}(V, V)
$$

Onde:

$\bar{\gamma}\left(x_{1}, x_{2}\right)$ é o variograma médio entre $x_{1}$ e $x_{2}$;

$\bar{\gamma}\left(x_{1}, V\right)$ é o variograma médio entre $x_{1}$ e o bloco $V$ a ser estimado;

$\bar{\gamma}(V, V)$ é o variograma médio do bloco em relação a si próprio.

A variável utilizada na krigagem foi o efeito líquido obtido no método estrutural-diferencial e as unidades regionais são os municípios, tendo por base o centroide destes.

As curvas de níveis foram elaboradas com base em quatro intervalos — de 2006-07, 2007-08, 2008-09 e 2009-10. Elas permitem não só observar as áreas de maior crescimento no espaço como também construir um diagrama de fases para indicar o movimento da valorização dos imóveis no tempo.

Uma vez que os dados estão georreferenciados, utiliza-se econometria espacial para avaliar se variáveis macroeconômicas regionais e efeitos de vizinhança podem explicar parte do dinamismo habitacional, bem como estabelecer clusters regionais, como descrito a seguir. 


\subsection{Regressão espacial e clusters espaciais}

O modelo de regressão clássica não capta o efeito do espaço em suas estimações. Se a localização for fator relevante para a explicação do fenômeno em questão, os parâmetros estimados serão viesados, pois se estará cometendo um erro de especificação. A dependência espacial pode ser incorporada de duas formas. A primeira, como um regressor adicional na forma de uma variável dependente defasada espacialmente; a segunda, como estrutura de erro (Anselin, 1999).

Logo, o modelo a ser estimado será:

$$
y=\rho W y+X \beta+\varepsilon
$$

Onde:

$y=$ vetor contendo a variável dependente;

$\rho=$ coeficiente espacial autorregressivo;

$W=$ matriz de vizinhança espacial ou matriz de ponderação espacial;

$X=$ matriz contendo as variáveis independentes;

$\beta=$ vetor dos parâmetros estimados;

$\varepsilon=$ vetor de erro que condiciona a incorporação do transbordamento espacial da seguinte forma:

1. se: $\varepsilon \rightarrow \mathrm{N}\left(0, \sigma^{2}\right)$, então: $\rho \neq 0$. Logo, o modelo a ser estimado é o de defasagem espacial;

2. se: $\varepsilon=\lambda W \varepsilon+\xi$, com $\lambda \neq 0$ e $\xi \rightarrow \mathrm{N}\left(0, \sigma^{2}\right)$, então, $\rho=0$. Logo, o modelo a ser estimado é o de erro espacial.

As hipóteses nulas são:

- Para defasagem espacial - $\mathrm{H}_{0}: \rho=0$;

v Para o modelo de erro espacial - $\mathrm{H}_{0}: \lambda=0$.

A avaliação inicial de especificação de regressão espacial deu-se pelo Índice de Moran (I-Moran). Esse índice é uma estatística de autocorrelação espacial que indica se a distribuição dos dados no espaço segue algum padrão não aleatório. Havendo algum padrão espacial para a variável que está sendo analisada, existem duas possibilidades: autocorrelação positiva ou negativa. Na primeira, os valores se aproximam no espaço; na segunda, os valores se distanciam espacialmente (Silva e Resende, 2005). Esse índice é calculado, segundo Florax e Graaff (2004), por:

$$
I=\frac{n}{S_{0}} \cdot \frac{\hat{\varepsilon}^{\prime} W \hat{\varepsilon}}{\hat{\varepsilon}^{\prime} \hat{\varepsilon}}
$$


Onde:

$n=$ número de observações;

$S_{0}=$ soma dos elementos da matriz de peso espacial $W$, considerando os dados não normalizados;

$\hat{\varepsilon}=$ vetor dos resíduos provenientes do Método dos Mínimos Quadrados Ordinários (MMQ);

$W=$ matriz de pesos espaciais.

Quando a estatística $I$ de Moran é próxima de +1 há autocorrelação positiva. Nesse caso, valores altos tendem a estar localizados na vizinhança de valores altos e valores baixos tendem a estar localizados na vizinhança de valores baixos. Se a estatística for próxima de -1, acontece o inverso: valores altos estarão cercados de valores baixos e valores baixos estarão cercados de valores altos. Quando I de Moran for zero não há autocorrelação espacial (Monasterio e Ávila, 2004). Os clusters espaciais foram formados a partir do I-Moran, tendo como base um nível de significância de 0,05 .

Uma vez confirmada a existência de influência do espaço, a decisão do modelo, se de defasagem ou de erro, deu-se conforme Anselin (2005). Utilizaram-se os testes de Multiplicadores de Lagrange $(L M)$, que são de dois tipos: Multiplicador de Lagrange de Defasagem Espacial (LM-lag) e Multiplicador de Lagrange de Erro Espacial (LM-error). Cada um desses tipos se subdivide em mais duas estatísticas. Assim, o LM-lag e o LM-error podem ser simples ou robustos. Dessa forma, se um dos dois LM-lag for significante $(<10 \%)$, há um indicativo a favor do modelo de defasagem espacial . Por outro lado, se o LM-error (simples ou robusto) for significante, ou seja, inferior a 10\%, há um indicativo a favor do modelo de erro espacial. A opção por um ou outro método de estimação deu-se por aquela estatística que fosse mais significante.

A construção da matriz de pesos espaciais $W$ permite relacionar uma região com seus vizinhos que possuem valores semelhantes. Anselin (2005) afirma que habitualmente a matriz é baseada na contiguidade espacial. Esta, por sua vez, pode ser de três tipos: rook (lados em comum); bishop (vértices em comum); e queen (lados e/ou vértices em comum). Para este trabalho, a matriz de peso espacial foi gerada pelo método queen e o número de vizinhos foi 10. A determinação desse número de vizinhança se deu após a realização das estimações de 1 até 20 vizinhos. Essas estimações geraram uma amostra de betas, coeficiente de determinação e critérios de Akaike e Schwarz. Aqueles onde os parâmetros e os coeficientes de determinação tendiam à média eram os candidatos a definirem a magnitude do número de vizinhos. Após, fez-se a compatibilização entre ambos, e com os critérios de Akaike e Schwarz. A regressão que mais se aproximava destes critérios foi a de 10 vizinhos.

Os dados referentes aos valores dos imóveis transacionados nos municípios do estado do Rio Grande do Sul estão anualizados, referem-se ao período compreendido entre 2006 e 2010 e foram obtidos junto à Caixa Econômica Federal. Dessa forma, a presente análise contempla, exclusivamente, os financiamentos transacionados pela Caixa Econômica Federal, em todas as suas modalidades de concessão. Pode-se inferir que tal análise retrata bem o comportamento do mercado, uma vez que a Caixa é responsável pela concessão de $73 \%$ dos 
financiamentos habitacionais (Financiamento, 2010). A quantidade total de financiamentos viabilizados pela Caixa, nesse período, no Rio Grande do Sul, foi de pouco mais de $242 \mathrm{mil}$ unidades, segundo dados disponibilizados pela instituição para esta pesquisa.

Os valores de imóveis transacionados pela Caixa foram agrupados por município e por faixa de valor. Foram somados os valores venais de todos os imóveis financiados em determinado município, naquele ano, dentro de uma faixa de valor específica. Destaca-se que isso engloba todas as modalidades de financiamento, com origem em todas as fontes de recursos. Foram considerados apenas os imóveis avaliados até R \$ 500 mil, uma vez que acima desse valor as operações não são enquadradas no Sistema Financeiro da Habitação (SFH) ${ }^{2}$ (Caixa, 2011).

A segmentação das faixas de valores se deu conforme a tabela 1.

Tabela 1

Divisão dos valores dos imóveis por faixas

\begin{tabular}{|c|l|}
\hline FAIXAS DE VALOR & \multicolumn{1}{|c|}{ VALOR IMÓVEL $(V)$} \\
\hline 1 & $V \leq R \$ 30.000 .00$ \\
2 & $\mathrm{R} \$ 30.000,00<V \leq \mathrm{R} \$ 55.000 .00$ \\
3 & $\mathrm{R} \$ 55.000,00<V \leq \mathrm{R} \$ 80.000 .00$ \\
4 & $\mathrm{R} \$ 80.000,00<V \leq \mathrm{R} \$ 150.000 .00$ \\
5 & $\mathrm{R} \$ 150.000,00<V \leq \mathrm{R} \$ 500.000,00$ \\
\hline
\end{tabular}

Fonte: Elaboração própria.

Os dados macroeconômicos utilizados foram obtidos junto à Fundação de Economia e Estatística Siegfried Emanuel Heuser (FEE) e se referem ao último ano de sua disponibilização: o PIB per capita, de 2008; o Idese, de 2007; o Déficit Habitacional, de 2000; a Taxa de Urbanização, de 2006; a População, de 2009 (FEE Dados, 2011).

Os procedimentos metodológicos utilizados se complementam. O método estruturaldiferencial e a krigagem são importantes meios de se visualizar a dinâmica do volume de imóveis financiados pela Caixa Econômica Federal, nos municípios do Rio Grande do Sul. Também fornecem subsídios para uma melhor interpretação da regressão espacial proposta, que acrescenta algumas variáveis macroeconômicas, e será apresentada na seção seguinte.

\footnotetext{
${ }^{2}$ As operações enquadradas no SFH são aquelas onde o valor do imóvel não ultrapassa R\$ 500 mil e o valor de financiamento é inferior a $\mathrm{R} \$ 450$ mil. Imóveis avaliados acima de $\mathrm{R} \$ 500$ mil ou valor de financiamento superior a R\$ 450 mil não se enquadram no SFH (Caixa, 2011). Para este trabalho, todos os imóveis transacionados avaliados em até R 500 mil foram considerados enquadrados no SFH, independentemente do valor de financiamento das respectivas operações.
} 


\section{Análise dos resultados da aplicação do método estrutural-diferencial e da krigagem}

Esta seção apresenta os resultados encontrados através da aplicação do método estrutural-diferencial e a estimação das curvas de isovalor. Está dividida em três subseções: a primeira faz uma abordagem estrutural dos dados, identificando quais as faixas de valor mais dinâmicas; a segunda avalia a competitividade dos municípios, através da análise diferencial; a terceira faz algumas considerações acerca do efeito líquido obtido, através das curvas de nível elaboradas por meio das técnicas de krigagem.

\subsection{Efeito estrutural}

O efeito estrutural indicou que a faixa que mais cresceu no período foi a Faixa 5 (imóveis entre $\mathrm{R} \$ 150.000,01$ e R \$ 500.000,00), com uma trajetória semelhante ao observado nas Faixas 3 e 4. As faixas com crescimento negativo foram a 1 e 2, com maior queda na Faixa 1 (imóveis até $\mathrm{R} \$ 30.000,00)$, conforme pode ser observado no gráfico 1 .

\section{Gráfico 1}

Evolução do total do valor venal dos imóveis financiados pela Caixa no Rio Grande do Sul (em R\$ milhões), por faixa de valor, entre os anos de 2006 e 2010

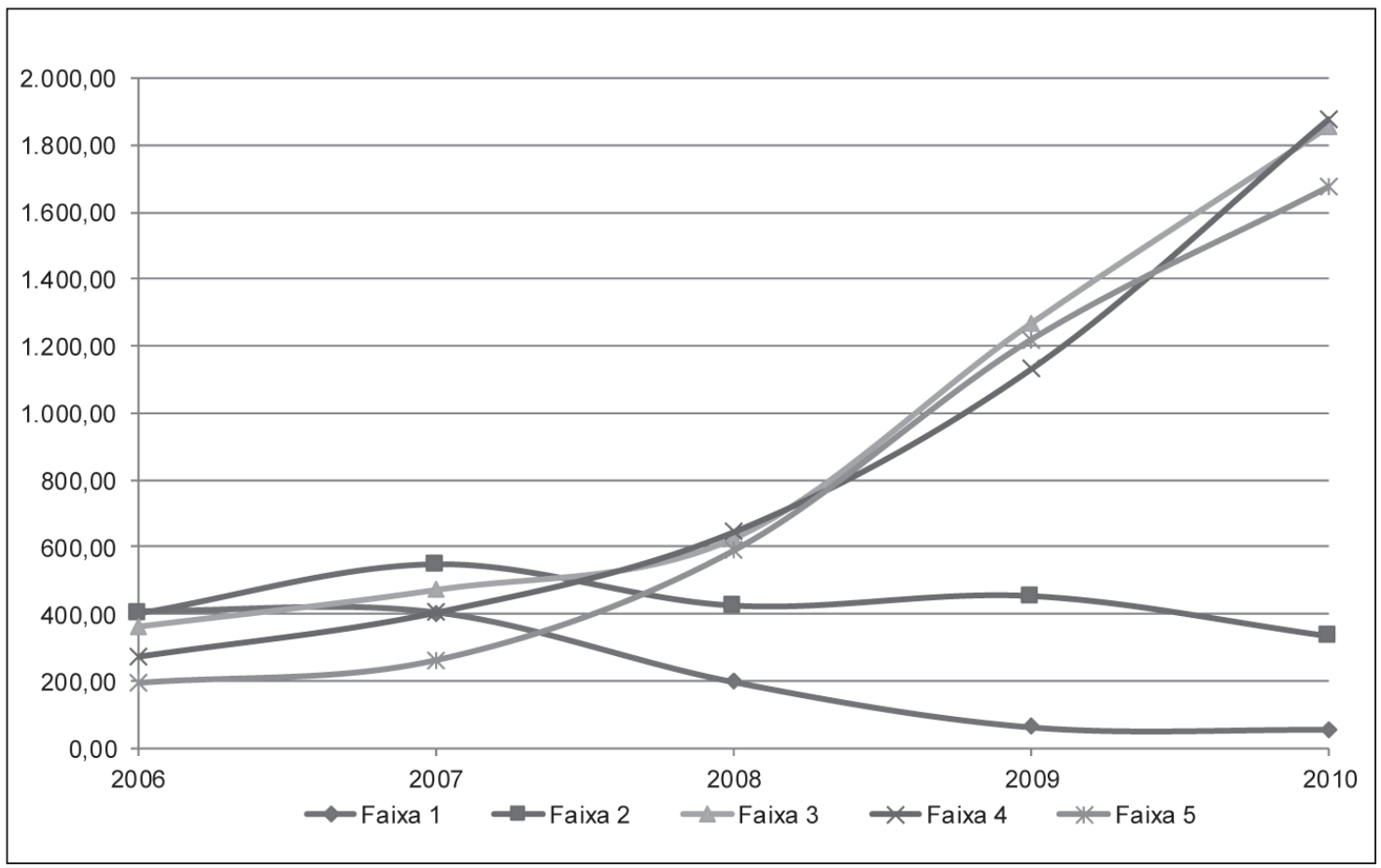

Fonte: Elaboração própria. 
Em síntese, verifica-se uma tendência de queda no volume de imóveis financiados, cujos valores venais foram avaliados em até R \$ 55 mil, acompanhada de uma trajetória ascendente do volume de imóveis nas faixas acima desse valor. Considerando ainda que o PMCMV contempla os imóveis localizados nas faixas de valores 3 e 4, e que estas apresentam um aumento considerável a partir da implantação do Programa — que ocorreu em 2009 —, pode-se inferir que o PMCMV tenha sido determinante para a taxa de crescimento.

\subsection{Efeito diferencial}

O estado do Rio Grande do Sul tem se caracterizado por um dinamismo dual. A parte sul do estado, denominada Metade Sul, apresenta baixo dinamismo, concentração na produção agropecuária com foco na pecuária de corte e criação de ovinos. Já as regiões da Serra, do Vale do Rio dos Sinos e a Metropolitana, localizadas no nordeste do estado, caracterizam-se por elevadas taxas de crescimento e alta concentração industrial. Essas diferenças de crescimento econômico resultaram em tal disparidade regional, onde uma pequena região situada no nordeste do Rio Grande do Sul detém 54\% do PIB do estado, em 2008 (FEE Dados, 2011).

Porém, essa estagnação no mercado imobiliário tem se modificado ao longo dos últimos anos. A avaliação do efeito diferencial obtido a partir do valor dos imóveis, no período de 2006 a 2010, mostra que ocorreu um incremento na Metade Sul do estado, em que os municípios apresentaram um maior efeito diferencial, como pode ser observado nos mapas apresentados na figura 2 .

\section{Figura 2}

Evolução dos efeitos diferenciais do valor venal dos imóveis financiados pela Caixa no Rio Grande do Sul entre 2006 e 2010

\begin{tabular}{|c|c|c|}
\hline Diferencial 2006-07 & Diferencial 2007-08 \\
\hline & &
\end{tabular}




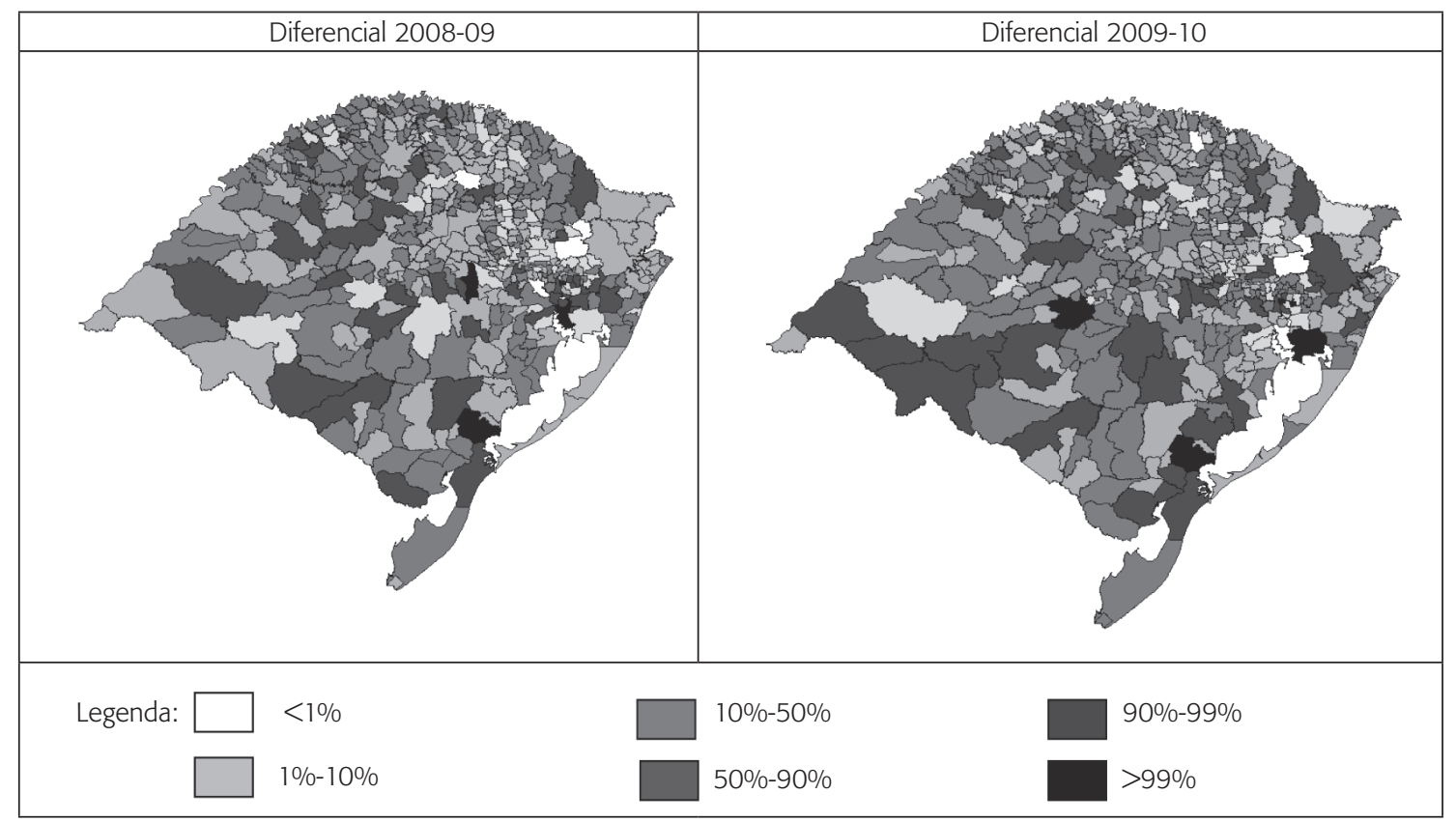

Fonte: Elaboração própria.

O único período em que houve um recuo do efeito diferencial, nos municípios da região sul e sudeste, foi o de 2008 a 2009, quando ocorreu a crise do subprime. Pode-se inferir que, dada a fragilidade econômica destas regiões, o impacto da crise foi maior do que nas demais. A região metropolitana perdeu competitividade no período de análise. É interessante ressaltar que o município de Viamão, vizinho de Porto Alegre, que era o de menor valor, apresentou um extraordinário crescimento. Esses dados revelam que ocorreu uma desconcentração da valorização dos imóveis.

\subsection{Efeito líquido}

O efeito líquido é a soma dos efeitos diferencial e estrutural. Indica os municípios mais dinâmicos por terem vantagens comparativas ou por terem concentração em faixas de valores que foram as mais dinâmicas. Dessa forma, é o indicador final da dinâmica de valorização locacional. Esse efeito foi utilizado na técnica de krigagem para determinar um mapa com diagrama de fase dos movimentos de valorização dos imóveis no Rio Grande do Sul. A figura 3 contém o mapa com este diagrama. 


\section{Figura 3}

\section{Dinâmica dos efeitos líquidos do valor dos imóveis financiados pela Caixa no Rio Grande do Sul entre 2006 e 2010}

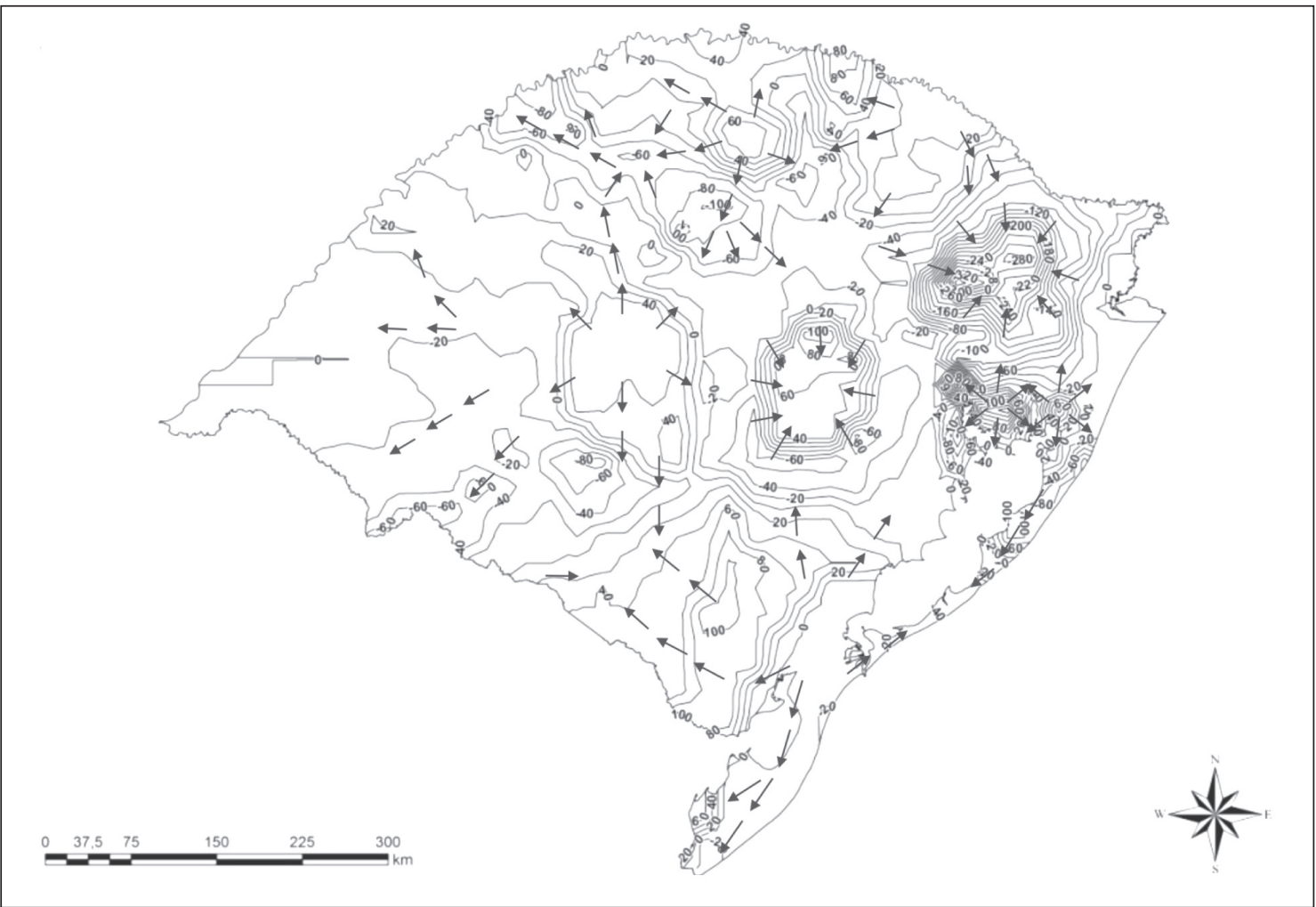

Fonte: Elaboração própria.

Obs.: 1) As setas indicam o sentido do deslocamento do Efeito Líquido do período de 2006 a 2010. 2) O município de Porto Alegre foi excluído da krigagem, uma vez que provocou um viés de concentração muito forte na capital, em virtude do grande volume e dos elevados valores de financiamentos realizados neste município.

A figura 3 contém o mapa e as curvas de isovalor com base no efeito líquido do primeiro período considerado (2006-07). A krigagem foi realizada para os quatro períodos e as setas da figura são vetores espaciais orientados em $\mathrm{V}^{2}$ pelo movimento do valor dado pelo efeito líquido, considerando os quatro períodos. Ela indica o deslocamento do efeito líquido de um centro de baixo valor para locais de alto valor.

A partir do diagrama da figura 3 verifica-se que ocorreu uma desconcentração do valor dos imóveis no Rio Grande do Sul no período analisado. Houve uma concentração dos valores dos financiamentos para o litoral, o sul e o sudoeste do estado, bem como para pontos da região central e da serra. Em contrapartida, a região metropolitana, o norte e o centro-oeste do Rio Grande do Sul apresentam uma dispersão. Em síntese, pode-se verificar que a política habitacional, associada à dinâmica econômica do estado, resultou em redução das disparidades 
no que se refere ao valor dos imóveis. Ainda, pode-se inferir que a dinâmica de concentração do crescimento que caracterizou o Rio Grande do Sul, por um longo período, pode estar perdendo força e o processo sendo revertido, se o mercado de imóveis for reflexo ou se refletir nos demais setores das economias locais.

Analisando o crescimento do efeito líquido, agregado por faixa de valores venais dos imóveis financiados pela Caixa Econômica Federal, verifica-se um movimento interessante que se refere às faixas 1 e 5, de menor e maior valor, respectivamente. Ambas partem de valores próximos no ano de 2007 (considerando valores do período final) e seguem trajetórias semelhantes, porém, inversas, em que a de menor valor cresce e a de maior valor decresce, e, em 2010, tornam-se, aproximadamente, iguais. O que de mais relevante ocorreu na economia neste período foi a crise do subprime e, em 2009, o início do PMCMV. Sem generalizar, pode-se inferir que os financiamentos das classes de menor renda foram menos sensíveis à crise econômica do que as de maior renda, e que o PMCMV, como visto anteriormente, concentrou recursos para faixas de rendas intermediárias (faixas 3 e 4), redimensionando as taxas de crescimento das faixas. Os dados dos valores do efeito líquido podem ser observados no gráfico 2 .

\section{Gráfico 2}

\section{Evolução do resultado líquido anual do valor venal dos imóveis financiados pela Caixa no Rio Grande do Sul (em R\$ milhões), por faixa de valor, entre os anos de 2006 e 2010}

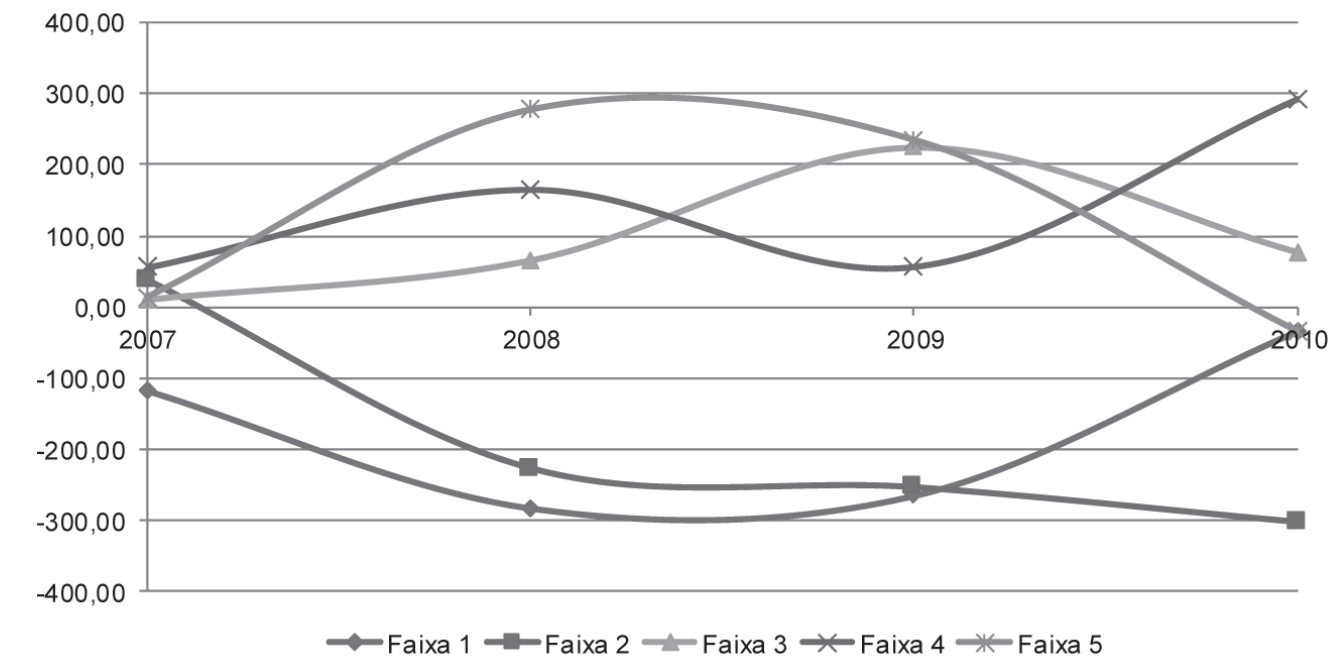

Fonte: Elaboração própria.

Ainda, da mesma forma que o observado no gráfico 1, a Faixa 4 foi a que apresentou o maior volume (médio) e apresentou crescimento de 2009-10 semelhante ao da Faixa 5.

Como síntese da aplicação do método estrutural-diferencial, foi possível verificar que, em termos de faixas, a dinâmica foi maior para as classes de maior renda, e que essa diferença foi ampliada pelo PMCMV. Já do ponto de vista espacial, verificou-se que ocorreu uma 
desconcentração de valores, migrando para áreas menos valorizadas dos imóveis. Ou seja, os municípios que, no início do período, apresentavam valores de imóveis depreciados, relativamente à média, passaram a ter maior valorização, ocorrendo o inverso para regiões que no início do período de análise possuíam elevados valores. A esse movimento atribuímos o impacto do PMCMV e a recuperação econômica ocorrida em 2010.

\section{Análise dos resultados da análise espacial}

Esta seção contém a análise de clusters e do modelo de regressão espacial, iniciando pelos clusters e concluindo com os resultados das estimativas da regressão espacial.

\subsection{Análise de clusters dos financiamentos}

Uma questão que acompanhou esta pesquisa foi se haveria regiões diferenciadas, em termos de captação dos empréstimos concedidos pela Caixa Econômica Federal, no período analisado. O método que foi utilizado para estabelecer os clusters, como descrito na seção de metodologia, foi através do I-Moran. A figura 4 contempla os mapas com os clusters dos valores fianciados no ano base, 2006, e, em 2010, ano final da pesquisa.

Figura 4

Clusters espaciais para os anos de 2006 e 2010 do total do valor financiado pela Caixa Econômica Federal no Rio Grande do Sul

Total do Valor Financiado em 2006 Total do Valor Financiado em 2010

Fonte: Elaboração própria. 
Ao analisar os mapas da figura 4, verifica-se que duas regiões formaram um cluster de elevados valores (Alto-Alto), nos dois períodos, que foram Região Metropolitana, Vale dos Sinos e Serra, no nordeste, e Pelotas e Rio Grande, no sul do estado. Em relação à primeira, localizada na região mais rica e dinâmica do estado, esperava-se que formasse um cluster de altos valores com vizinhos de elevados valores.

Já o cluster localizado no sul, que contempla a cidade de Rio Grande, foi a região que mais cresceu no estado, em 2008, como consequência, basicamente, da instalação do polo naval. Rio Grande e Pelotas eram municípios que estavam deprimidos economicamente mas, a partir do desenvolvimento da produção de uma plataforma para a Petrobras, ocorreu uma demanda intensa por moradias, tendo se valorizado intensamente os preços dos imóveis. Isso explicaria a formação desse cluster.

Outro aspecto interessante dos clusters é que ocorreu uma redução das regiões com nível muito baixo de captação, como pode ser observado nos mapas da figura 3, em que os clusters Baixo-Baixo, localizados, basicamente, na região norte do Rio Grande do Sul, se reduziram no último período. Esse resultado reforça o obtido na técnica de krigagem, que evidenciou uma desconcentração de valores. Logo, a redução desses clusters confirma o resultado obtido e localiza as regiões onde esse efeito foi mais significativo.

\subsection{Regressão espacial}

Para a realização da regressão espacial, foram realizadas diversas estimações com uma ampla gama de variáveis. Algumas provenientes do banco de dados disponibilizado pela Caixa, outras provenientes de dados macroeconômicos dos municípios, obtidos junto à FEE.

Essas variáveis foram testadas para avaliar a capacidade de explicação das variações no volume de imóveis financiados pela Caixa no período de 2006 a 2010, em dados de corte para cada ano. Como é uma análise exploratória, fez-se uma regressão com todas as variáveis que foram selecionadas e se excluíram as não significantes, pelo teste da razão de máxima verossimilhança (LR), para avaliar variáveis redundantes e, ao mesmo tempo, analisar a estabilidade dos parâmetros estimados pelo teste de Wald. ${ }^{3}$ As variáveis relevantes, que permaneceram nas regressões, estão discriminadas no quadro 1.

\footnotetext{
${ }^{3} \mathrm{O}$ teste $\mathrm{LR}$ é dado por $\mathrm{LR}=2\left(\mathrm{l}_{\mathrm{ir}} \mathrm{-}_{\mathrm{r}}\right) \sim \chi^{2}(\mathrm{mgl})$. Onde LR é o teste da razão de máxima verossimilhança; 1 é o logaritmo da função de verossimilhança restrita (r) e irrestrita (ir); LR segue uma distribuição qui-quadrado com o número de graus de liberdade igual ao número de restrições impostas ao modelo (Gujarati, 2006). O teste de Wald (Wt) testa restrições sobre os parâmetros estimados e é calculado supondo $\mathrm{y}=\mathrm{X} \beta+\varepsilon$, com restrições lineares $\mathrm{R} \beta=\mathrm{r}$, por: $W t=\frac{(R \hat{\beta}-r)^{\prime}\left[R\left(X^{\prime} X\right)^{-1} R^{\prime}\right]^{-1}(R \hat{\beta}-r) / q}{\left(e^{\prime} e\right)(n-k)} \sim F(q, n-k)$ Wt segue uma distribuição $\mathrm{F}$ e a definição dos graus de liberdade dada na equação dependem de q, o número de restrição, e n-k, número de observações menos o número de parâmetros estimados (Soares e Castelar, 2003).
} 


\section{Descrição das variáveis utilizadas na análise de regressão}

\begin{tabular}{|c|c|}
\hline VARIÁVEL & DESCRIÇÃO \\
\hline Financ & $\begin{array}{l}\text { Variável Dependente. Representa valor financiado dos imóveis transacionados pela Caixa Econômica } \\
\text { Federal no Rio Grande do Sul, no ano considerado. }\end{array}$ \\
\hline PIB_PC & $\begin{array}{l}\text { Produto Interno Bruto per capita ou Renda per capita - somatório de todos os bens e serviços finais } \\
\text { produzidos no município, dividido pelo número de habitantes. }\end{array}$ \\
\hline Idese & $\begin{array}{l}\text { Índice de Desenvolvimento Socioeconômico - objetiva mensurar e acompanhar o nível de desenvolvi- } \\
\text { mento do município. Abrange um conjunto amplo de indicadores sociais e econômicos, classificados em } \\
\text { quatro blocos temáticos: educação, renda, saneamento e domicílios. Varia de zero a um. }\end{array}$ \\
\hline Pop & População total do município. \\
\hline Área & Dimensão territorial do município em km². \\
\hline Taxa_Urb & Proporção de população urbana sobre a população total. \\
\hline Def_Hab & $\begin{array}{l}\text { Corresponde à necessidade de reposição total de unidades precárias e ao atendimento à demanda não } \\
\text { solvável nas condições dadas de mercado. }\end{array}$ \\
\hline Ag_Caixa & $\begin{array}{l}\text { Variável que indica se há ou não a presença de agências da Caixa no município. Atribuiu-se o valor um } \\
\text { quando há agência e zero quando não há. }\end{array}$ \\
\hline
\end{tabular}

Fonte: Elaboração própria.

Logo, o modelo estimado foi assim definido:

$$
\begin{aligned}
Y_{i}=\beta_{0}+\rho W y_{i}+ & \beta_{1} P I B_{-} P C i+\beta_{2} \text { IDESE }_{i}+\beta_{3} \text { Pop }_{i}+\beta_{4} \text { Área }_{i}+\beta_{5} \text { Taxa_Urb }_{i}+ \\
& \beta_{6} \text { Def_Hab }_{i}+\beta_{7} A g_{-} \text {Caixa }_{i}+\lambda W \varepsilon_{i}+\xi_{i}
\end{aligned}
$$

As hipóteses alternativas $\left(\mathrm{H}_{1}\right)$, em contraposição a $\mathrm{H}_{0}: \beta_{i}=0 \forall i$, foram: $\mathrm{H}_{1}: \beta_{1}>0 ; \mathrm{H}_{1}$ : $\beta_{2}>0 ; \mathrm{H}_{1}: \beta_{3}>0 ; \mathrm{H}_{1}: \beta_{4}<0 ; \mathrm{H}_{1}: \beta_{5}<0 ; \mathrm{H}_{1}: \beta_{6}>0 ; \mathrm{H}_{1}: \beta_{7}>0$. O argumento para estes efeitos baseia-se no fato de que o volume de financiamentos habitacionais deva ser crescente com o aumento do PIB per capita, do Índice de Desenvolvimento Socioeconômico maior (Idese), da população, do déficit habitacional e da existência de agência da Caixa Econômica Federal no município, uma vez que, quanto maior o poder aquisitivo e maior a população, mais contratos deveriam ser realizados. Já no que se refere ao déficit habitacional, as condições de crédito oferecidas pelo PMCMV deveriam permitir a alavancagem dessas regiões, até mesmo porque esta variável foi utilizada para determinar a distribuição dos recursos, em termos nacionais, para aplicação no PMCMV. A taxa de urbanização deveria ter impacto negativo porque essas regiões seriam menos competitivas na demanda habitacional para novas residências em relação àquelas com menores taxas. Da mesma forma, a área: municípios com maiores áreas foram aqueles que sofreram menores desmembramentos e, portanto, deveriam ter uma taxa de crescimento inferior aos que se emanciparam. No que se refere às agências da Caixa, era de se esperar que os financiamentos fossem alavancados pela facilidade de acesso às mesmas. 
No que se refere aos operadores de defasagem, espera-se que exista transbordamento espacial uma vez que os recursos são escassos e se um município intensificar sua taxa de financiamento deverá reduzir as dos vizinhos. Assim, as hipóteses nulas seriam $\mathrm{H}_{0}: \rho=0$ e $\mathrm{H}_{0}$ : $\lambda=0$ e as alternativas $\mathrm{H}_{1}: \rho<0$ e/ou $\mathrm{H}_{1}: \lambda<0$.

Antes de realizar a regressão, fez-se a análise das correlações entre as variáveis para avaliar a existência de multicolinearidade. Pelos valores destes, não foi detectada nenhuma correlação elevada que justificasse sua eliminação, exceto Taxa de Urbanização e Idese. A decisão foi de mantê-las inicialmente e avaliar o nível de significância de cada uma delas e o $\mathrm{R}^{2}$ ajustado; depois, eliminar alternativamente cada uma e comparar os níveis de significância e as alterações do coeficiente de terminação ajustado. Esse processo não revelou alterações significativas nos p-valores e nem no $\mathrm{R}^{2}$ ajustado, de forma que a decisão foi de mantê-las na regressão. Ainda, no que se refere ao déficit habitacional, optou-se por mantê-lo nas estimações independentemente de ser ou não significativo, uma vez que esta variável foi o elemento determinante das metas no PMCMV. A tabela 2 contém estas correlações.

Tabela 2

Correlação das variáveis independentes utilizadas no modelo

\begin{tabular}{|l|ccccccc|}
\hline \multicolumn{1}{|c|}{ Variáveis } & Ag_Caixa & Área & Def_Hab & Idese & PIB_PC & Pop & Taxa_Urb \\
\hline Ag_Caixa & 1,000 & - & - & - & - & - & - \\
Área & 0,343 & 1,000 & - & - & - & - & - \\
Def_Hab & $-0,064$ & $-0,009$ & 1,000 & - & - & - & - \\
Idese & 0,561 & 0,200 & $-0,010$ & 1,000 & - & - & - \\
PIB_PC & 0,130 & $-0,019$ & 0,017 & 0,297 & 1,000 & - & - \\
Pop & 0,347 & 0,154 & $-0,061$ & 0,312 & 0,078 & 1,000 & - \\
Taxa_Urb & 0,636 & 0,305 & $-0,135$ & 0,711 & 0,109 & 0,337 & 1,000 \\
\hline
\end{tabular}

Fonte: Elaboração própria.

As regressões indicaram que havia um elevado grau de dependência espacial, pois o $I$ Moran foi 0,0000, em 2006; 0,0079, em 2007; 0,0000, em 2008; 0,0875, em 2009 e 0,0034, em 2010. Em termos de estrutura de transbordamento espacial, somente em 2006, as estatísticas dos testes de Multiplicadores de Lagrange (LM) indicaram o modelo de erro espacial como adequado para estimação e a defasagem espacial para os demais anos. Ao realizar as estimativas conforme mencionado, obteve-se os resultados constantes na tabela 3.

Um dos resultados mais relevantes dessas estimações foi a constatação da existência de transbordamento espacial, pois corrobora com os resultados obtidos na conjunção do método estrutural-diferencial com a técnica de krigagem e revela que estudos que tratarem deste tema, do ponto de vista econométrico, deverão fazê-lo por regressão espacial. Caso contrário, estarão sujeitos a um viés de omissão de variável relevante e os resultados poderão ser viesa- 
dos. Ainda, sob os aspectos gerais, pode-se verificar que os níveis de explicação dos modelos foram elevados, em torno de $96 \%$.

Tabela 3

Resultados das estimações

\begin{tabular}{|c|c|c|c|c|c|}
\hline \multirow{2}{*}{ Variáveis } & \multicolumn{5}{|c|}{ Parâmetros / p-valor } \\
\hline & 2006 & 2007 & 2008 & 2009 & 2010 \\
\hline \multirow{2}{*}{ Constante } & -2.861 .60 & -4.470 .696 & 6.150 .060 & -8.174 .800 & -12.700 .000 \\
\hline & $(0,03)$ & $(0,02)$ & $(0,02)$ & $(0,09)$ & $(0,03)$ \\
\hline \multirow{2}{*}{ PIB_PC } & 14,78 & 34,45 & 51,42 & 88,50 & 97,98 \\
\hline & $(0,07)$ & $(0,00)$ & $(0,00)$ & $(0,00)$ & $(0,01)$ \\
\hline \multirow{2}{*}{ Idese } & 4.589 .27 & 7.267 .336 & 9.843 .900 & 13.800 .000 & 21.000 .000 \\
\hline & $(0,04)$ & $(0,02)$ & $(0,02)$ & $(0,00)$ & $(0,034)$ \\
\hline \multirow{2}{*}{ Pop } & 127,86 & 187,77 & 241,86 & 451,63 & 583,21 \\
\hline & $(0,00)$ & $(0,00)$ & $(0,00)$ & $(0,00)$ & $(0,00)$ \\
\hline \multirow{2}{*}{ Área } & $-878,63$ & $-1.382,73$ & $-1.949,29$ & $-3546,11$ & $-4.463,90$ \\
\hline & $(0,00)$ & $(0,00)$ & $(0,00)$ & $(0,00)$ & $(0,00)$ \\
\hline \multirow{2}{*}{ Taxa_Urb } & $-13.386,15$ & $-21.188,97$ & $-26.514,92$ & $-54243,35$ & $-54.251,30$ \\
\hline & $(0,01)$ & $(0,00)$ & $(0,03)$ & $(0,00)$ & $(0,02)$ \\
\hline \multirow{2}{*}{ Def_Hab } & $-10.039,24$ & $-14.221,65$ & $-26.112,62$ & $-49480,30$ & $-100350,4$ \\
\hline & $(0,70)$ & $(0,71)$ & $(0,063)$ & $(0,62)$ & $(0,41)$ \\
\hline \multirow{2}{*}{ Ag_Caixa } & $-862.683,70$ & -1.309 .42 & -1.499 .569 & -3.656 .193 & -3.147 .669 \\
\hline & $(0,00)$ & 0,0007785 & $(0,00)$ & $(0,00)$ & $(0,01)$ \\
\hline \multirow{2}{*}{$\rho \mathbf{W y}$} & - & $-0,11$ & $-0,12$ & $-0,12$ & $-0,11$ \\
\hline & & $(0,00)$ & $(0,00)$ & $(0,00)$ & $(0,00)$ \\
\hline \multirow{2}{*}{$\lambda \mathbf{W \varepsilon}$} & 0,35 & - & - & - & \\
\hline & $(0,00)$ & & & & \\
\hline $\mathbf{R}^{2}$ & 0.9643 & 0.9610 & 0.9547 & 0.9549 & 0.9604 \\
\hline
\end{tabular}

Fonte: Elaboração própria. 
Ainda no que se refere ao transbordamento espacial, o sinal desses operadores foram negativos, exceto para 2006, corroborando com a hipótese formulada de que haveria concorrência ao crédito que é limitado e essa concorrência aumentou nos anos de 2008 e 2009, e reduziu-se em 2010. As variáveis relacionadas ao efeito espacial ( $\lambda W \varepsilon$ e $\rho W y$ ) foram significantes a $1 \%$.

Em termos de influência das demais variáveis explicativas no nível financiamento, pode-se observar que o PIB per capita (PIB_PC), o Idese e a População (Pop) apresentaram sinal positivo, com maior significância para esta última variável. Esses efeitos confirmam as hipóteses formuladas em relação aos parâmetros das mesmas. É interessante observar que aumentou o impacto delas ao longo do período analisado. Este movimento conjunto pode estar indicando que os empréstimos foram se intensificando nas áreas menos dotadas de recursos e de menor população para as mais desenvolvidas e mais populosas. Uma justificativa para tal movimento, associando-se com os resultados das curvas de isovalor, poderia ser de que os municípios menores tenham tido um atendimento mais rápido de suas demandas habitacionais do que os maiores.

Já no que se refere ao Idese, que aborda aspectos de educação, renda, saneamento e domicílios e saúde, havia a expectativa de que ele apresentasse uma relação direta com o total do valor financiado porque, além da justificativa na hipótese formulada, algumas normas de viabilidade técnica dos empreendimentos, como saneamento, deveriam ser respeitadas para que houvesse liberação dos financiamentos habitacionais.

No que se refere às variáveis independentes que apresentaram relação inversa com a variável dependente, a área (Área) e a taxa de urbanização (Taxa_Urb) apresentaram os sinais esperados. Porém, no que diz respeito ao Déficit Habitacional (Def_Hab) e à existência de agência da Caixa Econômica Federal, no município (Ag_Caixa), esperava-se que as hipóteses associadas a essas variáveis fossem positivas, ou seja, os resultados rejeitaram as hipóteses relacionadas a estas variáveis.

No que se refere à Taxa de Urbanização, ela de fato não foi significante, ou seja, não se pode rejeitar a hipótese nula de que seu valor seja zero. Porém, chama a atenção o fato de a Ag_Caixa ter apresentado um sinal negativo e significante a 1\%. Mesmo que se argumentasse que os municípios que não possuem agência da Caixa Econômica Federal estão vinculados à uma agência localizada numa cidade próxima e que, portanto, isso não seria impedimento para a concessão de financiamento dos municípios sem agência, e que haveria uma democratização do acesso aos financiamentos pelo PMCMV, não se justificaria um sinal negativo para esta variável. Até mesmo porque ela ocorre em períodos em que não havia sido implementado o PMCMV. Assim, haveria a necessidade de se avaliar mais profundamente as causas desses resultados.

Em suma, as estimações revelaram a existência de efeito espacial e que esse efeito foi relativamente estável, ao longo do período analisado. Já as demais variáveis explicativas apresentaram impactos crescentes, entre 2006 e 2007, indicando uma intensificação das relações estabelecidas no modelo de regressão. 


\section{Considerações finais}

O déficit habitacional tem sido um problema histórico no Brasil e, ao longo de sua história recente, diversas políticas tentaram mitigá-lo, com destaque para a FCP, a criação do BNH e, mais recentemente, o Programa "Minha Casa, Minha Vida", implementado em 2009, no intuito de prover acesso à moradia pela população de baixa renda.

Partindo da importância das políticas habitacionais no contexto brasileiro, o presente trabalho teve por objetivo analisar os elementos impulsionadores dos financiamentos habitacionais e seus impactos em termos regionais, no Rio Grande do Sul, no período de 200610. Para isso, foram utilizados três procedimentos metodológicos complementares: o método estrutural-diferencial, as técnicas de krigagem e a análise de regressão.

Como resultados da análise proposta, podem-se inferir algumas constatações. A aplicação do método estrutural-diferencial e a técnica de krigagem possibilitaram a determinação de quais as faixas de valor de imóvel são as mais dinâmicas. Além disso, permitiram ver que ocorreu uma dispersão de financiamentos, entre 2006 e 2010, para o sul e o sudoeste do estado, que eram as regiões menos desenvolvidas economicamente, e que houve um deslocamento dos valores das áreas de autovalor para as de baixo valor, no período analisado.

Entretanto, é importante salientar que essa dispersão não significa que a população menos favorecida foi beneficiada, pois os métodos utilizados não permitiram inferir como se deu a distribuição dos recursos dentro de cada um dos municípios. Porém, pode-se afirmar que os municípios menos desenvolvidos economicamente foram beneficiados e que os imóveis, nestas localidades, sofreram um incremento significativo de valor, fatores que contribuem para a redução das desigualdades regionais.

Porém, um aspecto negativo foi o fato de que, mesmo com o PMCMV, as faixas de menor valor dos imóveis tiveram uma taxa de crescimento inferior às demais, o que indica a necessidade de estabelecer critérios mais positivos para o acesso à habitação para as classes menos favorecidas.

A análise de clusters contribuiu para compreender melhor os resultados anteriores, pois foi possível verificar que os municípios que captavam maiores recursos, em 2006, permaneceram os mesmos em 2010. Porém, aqueles que tiveram menor volume de financiamento, com um nível de significância de 5\%, em 2006, reduziram-se, em 2010, evidenciando uma melhora na distribuição para regiões menos favorecidas.

Com relação aos fatores macroeconômicos que poderiam explicar o volume de financiamento, pela análise de regressão espacial, confirmaram-se as hipóteses de que o volume de financiamentos habitacionais deva ser crescente com o aumento do PIB per capita, do Idese e da população, e, decrescente, com a área e a taxa de urbanização.

Porém, a hipótese de que o déficit habitacional teria impacto positivo, principalmente por ter sido a variável utilizada para distribuição dos recursos do PMCMV, não foi significativa em nenhum dos anos do período analisado; a presença de agência(s) da Caixa Econômica Federal no município também não estimulou o financiamento em níveis superiores aos demais municípios. Este resultado sugere a necessidade de estudos que possibilitem entender que me- 
canismos estão operando para este resultado, pois eles podem ser elementos importantes para o estabelecimento de políticas de expansão das agências da Caixa Econômica Federal.

Em suma, os resultados indicam que os elementos impulsionadores dos financiamentos habitacionais mantiveram a mesma tendência no período analisado, ou seja, nos anos anteriores à existência do Programa "Minha Casa, Minha Vida" (2006-08) e durante a vigência deste (2009-10). Mesmo que o crédito para famílias de baixa renda tenha se acelerado no período do PMCMV, atribui-se essa aceleração à crise do subprime que havia deprimido os créditos a esta parte da população, em prol das faixas de maior renda, de forma que, embora tenha tido elevada a taxa de crescimento, a Faixa 1 (menor renda) retornou aos patamares existentes em 2006. Logo, embora tenham se acelerado os volumes de crédito, os aspectos estruturais e as tendências deles permaneceram os mesmos. Portanto, pode-se afirmar que o impacto do PMCMV foi basicamente de aceleração do volume de crédito e de valorização dos imóveis de regiões menos desenvolvidas, o que permitiu uma redução das desigualdades regionais.

Além disso, este estudo avaliou a dinâmica dos financiamentos e da valorização dos imóveis em termos municipais, no Rio Grande do Sul. No processo de análise, detectou-se a relevância de estudar a dinâmica interna dos municípios, para avaliar se os fenômenos regionais encontrados, neste estudo, repetem-se, internamente, nos municípios.

\section{Referências}

ALVES, José E. D.; CAVENAGHI, Suzana. Déficit habitacional, famílias conviventes e condições de moradia. In: GUIMARÃES, José R. (Org.). Demografia dos negócios: campo de estudo, perspectivas e aplicações. Demographicas, Campinas, v. 3, p. 257-286, 2006.

ALVES, Tiago W. Análise da versão clássica do método estrutural-diferencial. Perspectiva Econômica, v. 33, n. 102, p. 5-22, 1998.

ANDRIOTI, José Leonardo S. Fundamentos de estatística e geoestatística. São Leopoldo: Unisinos, 2005.

ANSELIN, Luc. Exploring spatial data with GeoDa ${ }^{T M}$ : a workbook. Center of Spatially Integrated Social Science, University of Illinois. Urbana-Champaign: Illinois, 2005.

ANSELIN, Luc. Spatial econometrics. Texas: School of Social Sciences - University of Texas at Dallas, Richardson, 1999.

AZEVEDO, Sérgio; ANDRADE, Luis A. G. de. Habitação e poder: da Fundação da Casa Popular ao Banco Nacional da Habitação. Rio de Janeiro: Zahar Editores, 1982.

BONATES, Mariana F. O Programa de Arrendamento Residencial — PAR: acesso diferenciado à moradia e à cidade. Revista de Pesquisa em Arquitetura e Urbanismo (Risco), n. 7, p. 147-164, 2008.

BOTELHO, Adriano. O urbano em fragmentos: a produção do espaço e da moradia pelas práticas do setor imobiliário. São Paulo: Annablume; Fapesp, 2007. 
BRAGA, Elza M. F. Os labirintos da habitação popular (conjunturas, programas e atores). Fortaleza: Fundação Demócrito Rocha, 1995.

BRASIL. Ministério das Cidades. Minha Casa, Minha Vida. Cartilha. 2009c. Disponível em: < http:// www.cidades.gov.br/ministerio-das-cidades/arquivos-e-imagens-oculto/minha_casa_minha_vida1-1__CAIXA.pdf>. Acesso em: 22 ago. 2010.

BRASIL. Ministério das Cidades, Secretaria Nacional da Habitação. Caderno Habitação. Política Nacional de Habitação. Brasília, 2004. Disponível em: <www.cidades.gov.br/secretarias-nacionais/ secretaria-de-habitacao/politica-nacional-de-habitacao/4PoliticaNacional Habitacao.pdf $>$. Acesso em: 21 ago. 2010.

BRASIL. Ministério das Cidades, Secretaria Nacional de Habitação. Déficit habitacional no Brasil 2007. Brasília, 2009a. Disponível em: <www.cidades.gov.br/ secretarias-nacionais/secretaria-de-habitacao/ biblioteca/publicacoes-e-artigos/DeficitHabita cional.zip/ view>. Acesso em: 21 ago. 2010.

BRASIL. Presidência da República. Lei $n^{\circ}$ 11.977, de 07 de julho de 2010. Dispõe sobre o Programa Minha Casa, Minha Vida - PMCMV e a regularização fundiária de assentamentos localizados em áreas urbanas. Brasília, 7 de julho de 2009b. Disponível em: <www.planalto.gov.br/legislacao/_ Ato2007-2010/2009/Lei/L11977.htm>. Acesso em: 15 nov. 2010.

BRASIL. 2009d. Presidência da República. Medida Provisória no 459, de 25 de março de 2009. Dispõe sobre o Programa Minha Casa, Minha Vida - PMCMV e a regularização fundiária de assentamentos localizados em áreas urbanas. Brasília, 24 de março de 2009. Disponível em: <www.planalto.gov. br/ccivil_03/_Ato2007-2010/2009/Mpv/459.htm>. Acesso em: 15 nov. 2010.

BROWN, James H. Shift and shareprojections of regional economic growth: an empirical test. Journal of Regional Science, v. 9, n. 1, p. 1-17, 1969.

CAIXA ECONÔMICA FEDERAL. Carta de crédito FGTS individual. 2011. Disponível em: <www. caixa.gov.br/habitacao>. Acesso em: 10 set. 2011.

CBIC. Câmara Brasileira da Indústria da Construção. Minha Casa não atinge meta em 9 estados. 2011. Disponível em: <www.cbic.org.br/sala-de-imprensa/noticia/minha-casa-nao-atinge-metaem-9-estados>. Acesso em: 28 mar. 2011.

DINC, Mustafa; HAYNES, Kingsley E. Regional efficiency in the manufacturing sector: integrated shift-share and data envelopment analysis. Economic Development Quarterly, v. 13, n. 2, p. 183-199, maio 1999. Disponível em: <http://edq.sagepub.com/ cgi/content/abstract/13/2/183>. Acesso em: 21 maio 2008.

DRUCK, Suzana et al. Análise espacial de dados geográficos. Brasília: Embrapa, 2004.

FEE DADOS. Fundação de Economia e Estatística Siegfried Emanuel Heuser. Indicadores. 2011. Disponível em: <www.fee.tche.br/feedados/consulta/menu_consultas.asp?tp_Pesquisa=var_Anual>. Acesso em: 15 jan. 2011.

FINANCIAMENTO habitacional pela Caixa cresce 126\% até abril. 2010. Disponível em: < http:// g1.globo.com/economia-e-negocios/noticia/2010/04/financiamento-habitacional-cresce-126-ateabril-diz-caixa.html> . Acesso em: 30 jan. 2011. 
FLORAX, Raymond J. G. M.; GRAAFF, Thomas de. The performance of diagnostic tests for spatial dependence in linear regression models: a meta-analysis of simulation studies. In: ANSELIC, Luc; FLORAX, Raymond J. G. M.; REY, Sergio J. (Org.). Advances in spatial econometrics: methodology, tools and applications. Nova York: Springer, 2004. p. 29-65.

FOTOPOULUS, Georgios. Integrating firm dynamics into the shift-share framework. Growth and Change, v. 38, n. 1, p. 140-152, 2007. Disponível em: < http://onlinelibrary. wiley.com/doi/10.1111/ j.1468-2257.2007.00356.x/abstract>. Acesso em: 22 jan. 2011.

GONÇALVES, Robson R. O déficit habitacional brasileiro: um mapeamento por unidades da federação e por níveis de renda domiciliar. Ipea - Texto para Discussão n. 559. Rio de Janeiro: Ipea, 1998.

GUJARATI, D. Econometria básica. 4. ed. Rio de Janeiro: Elsevier Campus, 2006.

HERSEN, Amarildo; LIMA, Jandir F. de. Crescimento regional estrutural-diferencial nas unidades federativas brasileiras no período de 1994-2004. VOOS Revista Polidisciplinar Eletrônica da Faculdade de Guairacá, Guarapuava, v. 1, n. 1, p. 31-50, jul. 2009. Disponível em: <www.revistavoos.com. br/seer/index.php/ voos/article/view/6>. Acesso em: 15 jan. 2011.

HIRATA, Francini. "Minha Casa, Minha Vida": política habitacional e de geração de emprego ou aprofundamento da segregação urbana? Revista Aurora, v. 2, n. 2, p. 1-11, jul. 2009.

LANDIM, Paulo M. B. Análise estatística de dados geológicos. 2. ed. São Paulo: Unesp, 2003.

LODDER, Celsius A. Crescimento da ocupação regional e seus componentes. In: HADDAD, Paulo (Org.). Planejamento regional: métodos e aplicações ao caso brasileiro. Rio de Janeiro: Ipea/Inpes, 1972.

MONASTERIO, Leonardo M.; ÁVILA, Rodrigo P. Uma análise espacial do crescimento econômico do Rio Grande do Sul (1939-2001). In: ENCONTRO NACIONAL DE ECONOMIA, XXXII, 2004, João Pessoa. Anais... Paraíba: Anpec, 2004. v. 5, n. 2, p. 269-296.

MULLIGAN, Gordon F.; MOLIN, Andreas. Estimating population change with a two-category shiftshare model. The Anais of the Regional Science, v. 38, n. 1, p. 113-130, 2004. Disponível em: <www. springerlink.com/content/aym1061wuwtc 37ch/>. Acesso em: 22 jan. 2011.

NAZARA, Suahasil; HEWINGS, Geoffrey J. D. Spatial structure and taxonomy of decomposition in shift-share analysis. Growth and Change, v. 35, n. 4, p. 476-490, 2004. Disponível em: <http://onlinelibrary.wiley.com/doi/10.1111/j.1468-2257.2004.00258.x/abstract>. Acesso em: 22 jan. 2011.

O CRÉDITO imobiliário no Brasil: caracterização e desafios. FGV Projetos. São Paulo: FGV, 2007. Disponível em: <www.abecip.org.br/imagens/conteudo/publicacoes_e_artigos/trabalho_fgv.pdf>. Acesso em: 13 fev. 2011.

PEREIRA, André da S.; CAMPANILE, Nicole. O método estrutural-diferencial modificado: uma aplicação para o estado do Rio de Janeiro entre 1986 e 1995. Teoria e Evidência Econômica, v. 7, n. 13, p. 121-140, nov. 1999.

PEREIRA, Gabriela M. Acessibilidade espacial na habitação popular: um instrumento para avaliação de projetos. Dissertação (mestrado em arquitetura e urbanismo) — Universidade Federal de Santa Catarina, Florianópolis, 2007. 
ROLNIK, Raquel. O programa Minha Casa, Minha Vida está avançando, mas apresenta alguns problemas. jun. 2010. Disponível em: < http://raquelrolnik.wordpress.com/2010/06/17/o-programaminha-casa-minha-vida-esta-avancando-mas-apresenta-alguns-problemas/>. Acesso em: 14 out. 2010.

SANTOS, Cláudio H. M. Políticas federais de habitação no Brasil: 1964/1998. Ipea — Texto para Discussão n. 654. Rio de Janeiro: Ipea, 1999.

SILVA, Alexandre M. A. da; RESENDE, Guilherme M. A importância do acesso aos serviços públicos na renda por habitante dos municípios nordestinos. Ipea - Texto para Discussão n. 1132. Rio de Janeiro: Ipea, 2005.

SILVA, Maria O. da S. Política habitacional brasileira: verso e reverso. São Paulo: Cortez, 1989.

SOARES, Ilton G.; CASTELAR, Ivan. Econometria aplicada com o uso do Eviews. Fortaleza: UFC, 2003.

SOBRAL, Filipe; PECI, Alketa; SOUZA, Gustavo C. de. Uma análise shift-share da dinâmica do setor de turismo no Brasil: recomendações para as políticas públicas. In: ENCONTRO DA ANPAD, XXX, Salvador, 2006.

SOUZA, Marco A. A. de. Geração de emprego na pesca industrial em Rio Grande: uma aplicação do método estrutural-diferencial. In: CONGRESSO DA SOBER, XLV, 2007, Londrina. Anais... Disponível em: <www.sober.org.br/palestra/6/589.pdf>. Acesso em: 22 jan. 2011. p. 1-12.

SOUZA, Nali de J. de; RODRIGUES, Matheus P. da F. Da evolução do emprego dos setores econômicos dos Coredes do Rio Grande do Sul, 1990/2000. Análise, v. 15, n. 2, p. 435-463, 2004.

WARNOCK, Veronia Cacdac; WARNOCK, Francis E. Markets and housing finance. Journal of Housing Economics, v. 17, n. 3, p. 239-251, 2008.

Cátia Fernanda da Silva é mestre em economia e professora auxiliar da Unisinos. E-mail: catiafs@unisinos.br.

Tiago Wickstrom Alves é doutor em economia e professor titular da Unisinos. E-mail: twa@unisinos.br. 